\title{
PENGARUH DISIPLIN KERJA TERHADAP KINERJA KARYAWAN (PADA PT. BANK DANAMON TBK CABANG BINTARO)
}

\author{
Bachtiar Arifudin Husain, S.KOM.,M. M. \\ Dosen Fakultas Ekonomi Universitas Pamulang \\ Email : $\underline{\text { dosen1773@unpam.ac.id }}$
}

\begin{abstract}
ABSTRAK
Tujuan dari penelitian ini dilakukan dengan tujuan untuk mengetahui disiplin kerja. Untuk mengetahui kinerja karyawan dan untuk mengetahui seberapa besar Pengaruh Disiplin Kerja Terhadap Kinerja Karyawan dan instansi yang menjadi obyek dalam penelitian ini adalah karyawan PT.Bank Danamon Tbk Cabang Bintaro.

Metode yang digunakan dalam penelitian ini adalah metode deskriptif kuantitatifdengan tehnik pengambilan sampel proporsional random sampling. Metode analisis data menggunakan deskriptif dan verifikatif dengan analisis regresi, determinasi, serta pengujian hipotesis.

Hasil penelitian menunjukkan bahwa disiplin kerja berpengaruh positif dan signifikan terhadap kinerja karyawan dengan kontribusi pengaruh sebesar $60,8 \%$ sedangkan sisanya sebesar 39,2\% dipengaruhi faktor lain. Pengujian hipotesis diperoleh $\mathrm{t}$ hitung $>\mathrm{t}$ tabel $(12,329>1,984)$ hal itu konsisten dengan nilai probability signification $<0,05$ dengan demikian $\mathrm{H}_{0}$ ditolak dan $\mathrm{H}_{1}$ diterima artinya terdapat pengaruh yang positif dan signifikan antara disiplin kerja terhadap kinerja Karyawan
\end{abstract}

Kata Kunci : Disiplin Kerja dan Kinerja Karyawan. 


\section{PENDAHULUAN}

Manajemen sumber daya manusia merupakan usaha untuk menggerahkan dan mengelola organisasi agar tujuan organisasi dapat tercapai. Hasibuan (2013:12) menyampaikan "Manajemen merupakan ilmu dalam mengatur pemanfaatan sumber daya manusia secara efektif untuk mencapai suatu tujuan tertentu". Dorongan karyawan dalam menjalankan kewajibannya sangat penting karena manusia merupakan salah satu unsur yang dapat berperan aktif dalam kebijakan dan pencapaian tujuan organisasi. Dengan sumber daya manusia yang handal maka kegiatan operasional perusahaan akan berjalan dengan lancer artinya unsur manusia memegang peranan penting dalam melakukan aktivitas untuk pencapaian tujuan.

Guna mencapai kondisi yang lebih baik, maka dituntut adanya Manajemen terhadap sumber daya manusia secara memadai sehingga terciptalah sumber daya manusia yang berkualitas, loyal dan berprestasi. Cakupan dari Manajemen Personalia menurut Dessler Gerry (2012:45)yang menjadi pekerjaan dalam manajemen personalia adalah "Analisis pekerjaan, perencanaan kebutuhan tenaga kerja dan pendaftaran calon pegawai, seleksi calon pegawai, orientasi dan pelatihan pegawai baru, manajemen upah dan gaji, penyediaan insentif dan kesejahteraan, penilaian prestasi kerja, komunikasi tatap muka, penyuluhan, dan pengembangan".

Karyawan dan perusahaan merupakan dua hal yang tidak dapat dipisahkan, karyawan memegang peran utama dalam menjalankan kegiatan perusahaan. Untuk memperoleh kemajuan dan mencapai tujuan yang telah ditetapkan, suatu perusahaan perlu menggerakkan serta memantau pegawainya agar dapat mengembangkan kemampuan yang dimilikinya. Sumber daya manusia merupakan salah satu faktor yang ikut terlibat secara langsung dalam menjalankan kegiatan perusahaan dan berperan penting dalam meningkatkan produktivitas perusahaan dalam mencapai tujuan yang telah ditetapkan.

PT. Bank Danamon telah bertekad untuk menjadi lembaga keuangan terkemuka di Indonesia yang keberadaannya diperhitungkan. Danamon bertujuan mencapai posisi ini dengan menjadi organisasi yang berpusat pada nasabah; yang melayani semua segmen, dengan menawarkan nilai yang unik untuk masing-masing segmen; berdasarkan keunggulan penjualan dan pelayanan, dengan didukung oleh teknologi kelas dunia. Sejalan dengan upaya ini, Danamon beraspirasi menjadi perusahaan pilihan untuk berkarya dan dihormati oleh semua pihak pemangku kepentingan, sementara memegang teguh kelima nilai perusahaan yaitu: peduli, jujur, mengupayakan yang terbaik, kerjasama, dan profesionalisme yang disiplin.

Disiplin kerja yang baik mencerminkan besarnya rasa tanggung jawab seseorang terhadap tugas-tugas yang diberikan kepadanya, Hal ini dapat mendorong gairah kerja, semangat kerja, efisiensi, serta efektivitas kerja karyawan. Dan tentunya hal ini akan berimbas pada output hasil kerjanya. Di tengah perhelatan perdagangan bebas, setidaknya Indonesia telah memiliki bekal berupa UU Perdagangan. Suatu organisasi dapat berjalan efektif apabila fungsi-fungsi manajemen seperti perencanaan, pengorganisasian, motivasi, kedisiplinan dan pengawasan yang ada di dalamnya berfungsi dengan baik, serta unsur-unsur penunjangnya tersedia dan memenuhi persyaratan. Salah satu unsur terpenting yang dapat mendukung jalannya perusahaan adalah sumber daya manusia (pegawai). Tenaga kerja atau sumber daya manusia dapat diartikan sebagai karyawan, pekerja atau pegawai yang memiliki keahlian dibidangnya masing-masing pada hakikatnya mempunyai maksud yang sama 
untuk mencapai suatu tujuan organisasi atau perusahaan.

Disiplin merupakan kesadaran dan kesediaan seseorang menaati peraturan semua perusahaan dan norma-norma sosial yang berlaku. Adapun arti kesadaran adalah sikap seseorang yang secara sukarela mentaati semua peraturan dan sadar akan tugas dan tanggung jawabnya. Disiplin yang tinggi akan memacu dan mendorong semangat kerja untuk berkinerja dengan baik sesuai dengan yang diinginkan organisasi. Hal ini selaras dengan pendapat Hasibuan (2013:98) dimana disampaikan bahwa "Disiplin merupakan kesadaran dan kesediaan seseorang mentaati semua peraturan perusahaan dan norma-norma sosial yang berlaku".

Dalam pelaksanaan tugas sehari-hari kedisiplinan sering menjadi kendala dalam sebuah organisasi, rendahnya kedisiplinan menjadi persoalan yang berulang-ulang terjadi. Dari hasil prariset yang penulis lakukan, berikut ini ketimpangan yang terjadi dimana disaat perusahaan sedang menggalakkan program kinerja yang berdayaguna namun justru pada perusahaan ini disiplin kerja menunjukkan trend yang kurang baik, Pelayanan yang prima belum dijalankan sebagaimana mestinya, misalnya datang terlambat, sering meninggalkan pekerjaan sebelum pada waktunya. Kondisi tersebut ditunjukkan pada data tabel berikut ini:

Absensi Karyawan PT. Bank Danamon Cabang Bintaro

\begin{tabular}{|l|c|c|c|c|}
\hline \multirow{2}{*}{ Bulan } & \multicolumn{4}{|c|}{ Kriteria } \\
\cline { 2 - 5 } & Terlambat & Ijin & Alpha & $\begin{array}{c}\text { Pulang } \\
\text { awal }\end{array}$ \\
\hline Januari & 8 & 10 & 6 & 10 \\
\hline Pebruari & 10 & 12 & 7 & 14 \\
\hline Maret & 11 & 13 & 8 & 15 \\
\hline April & 10 & 14 & 10 & 16 \\
\hline Mei & 12 & 15 & 12 & 16 \\
\hline
\end{tabular}

\begin{tabular}{|l|c|c|c|c|}
\hline Juni & 13 & 15 & 11 & 17 \\
\hline Juli & 14 & 17 & 12 & 18 \\
\hline Agustus & 13 & 18 & 14 & 16 \\
\hline September & 15 & 20 & 16 & 17 \\
\hline
\end{tabular}

Sumber : PT. Bank Danamon Tbk Cabang Bintaro

Berdasarkan data tabel di atas, menunjukkan bahwa tingginya absensi karyawan pada bulan Januari sampai dengan September 2015 secara keseluruhan dalam kondisi yang kurang baik, dimana dari keseluruhan karyawan baik yang datang terlambat, ijin, tanpa ijin, maupun pulang lebih awal menunjukkan trend yang meningkat, hal ini mengindikasikan masih banyaknya karyawan yang kurang disiplin kerjanya.

Veithzal Rivai Ahmad Fawzi (2012:15) menyampaikan "Kinerja merupakan seperangkat hasil yang dicapai dan merujuk pada tindakan pencapaian serta pelaksanaan sesuatu pekerjaan yang ditetapkan organisasi". Sedarmayanti (2012:156) kinerja didefinisikan sebagai "Catatan mengenai outcome yang dihasilkan dari suatu aktivitas tertentu, selama kurun waktu tertentu pula". Sedangkan Robbins (2012:226) berpendapat bahwa "Kinerja adalah suatu hal yang sangat penting karena dapat digunakan sebagai masukan untuk membuat keputusan". Lebih lanjut Robbins (2012:227) menjelaskan "Niat untuk bekerja menuju sasaran merupakan sumber utama dari motivasi kerja. Artinya sasaran sebagai acuan karyawan tentang apa yang akan dikerjakan dan berapa banyak upaya yang akan dilakukan". Rendahnya kinerja dan motivasi karyawan yang dihadapi sebenarnya merupakan permasalahan klasik namun selalu up to date untuk didiskusikan. Sumber daya manusia adalah potensi yang merupakan aset dan berfungsi sebagai modal di dalam organisasi.

Disiplin kerja dalam penelitian ini, berhubungan dengan tingginya kinerja 
organisasi. Dengan kata lain, makin tinggi disiplin kerja, maka makin tinggi pula kinerja yang dihasilkan karyawan, sehingga pada akhirnya karyawan mau dan ikhlas bekerja dengan sebaik mungkin demi tercapainya tujuan organisasi dan berbagai sasarannya. Setiap organisasi mengharapkan pegawai dapat berkinerja dengan baik. Informasi mengenai kinerja pegawai diperoleh melalui penilaian kinerja. Hasibuan (2013:100) berpendapat "Hasil kerja yang dicapai setiap karyawan sehingga dapat memberikan kontribusi positif terhadap perusahaan". Dari hasil evaluasi kinerja pegawai dapat diketahui apakah seorang pegawai dapat bekerja dengan baik atau tidak yang dilihat dari kategori penilaian yang dibandingkan antara tolok ukur penilaian kinerja organisasi dengan kinerja pegawai.

Berikut ini hasil evaluasi penilaian kinerja karyawan yang diambil secara secara rata-rata di PT. Bank Danamon Tbk Cabang Bintaro. periode bulan Februari April 2015 sebagai berikut :

Pengukuran Kinerja Program (PKP)

\begin{tabular}{|c|c|c|c|c|}
\hline \multirow{2}{*}{ Komponen } & \multicolumn{3}{|c|}{ Pencapaian } & \multirow{2}{*}{ Kriteria } \\
\cline { 2 - 4 } & Tercapai & Tidak & $\%$ & \\
\hline Pelayanan & 77 & 56 & $58 \%$ & Sedang \\
\hline Kepatuhan & 69 & 64 & $52 \%$ & Sedang \\
\hline Ketegasan & 73 & 60 & $55 \%$ & Sedang \\
\hline Integritas & 72 & 61 & $54 \%$ & Sedang \\
\hline Kerjasama & 69 & 64 & $52 \%$ & Sedang \\
\hline Kepemimpinan & 82 & 51 & $62 \%$ & Cukup \\
\hline MotivasiKaryawan & 68 & 65 & $51 \%$ & Sedang \\
\hline Pencapaian kerja & 70 & 63 & $53 \%$ & Sedang \\
\hline Prestasi kerja & 67 & 66 & $50 \%$ & Buruk \\
\hline Tanggung jawab & 74 & 59 & $56 \%$ & Sedang \\
\hline Rata-rata & 60,9 & 72,1 & $54 \%$ & Sedang \\
\hline
\end{tabular}

Kriteria (\%): 1-50 = Buruk, 51-60 = Sedang, $61-70=$ Cukup,

71-80 = Baik, 81-99 = Sangat Baik

Berdasarkan data tabel di atas menunjukkan bahwa dari total 133 karyawan, pencapaian kerja berada pada tataran yang masih terkoreksi. Evaluasi yang dilakukan merupakan salah satu upaya untuk mengetahui kemajuan organisasi. Penilaian yang dilakukan oleh masih-masing kepala bagian yang kemudian dikumpulkan pada Human Resources Department (HRD) secara keseluruhan menunjukkan bahwa dari Pada aspek pelayanan hanya mampu mencapai 58\%, aspek kepatuhan 52\%, ketegasan $55 \%$, integritas $54 \%$, kerjasama $52 \%$, kepemimpinan $62 \%$, motivasi $51 \%$, pencapaian kerja $53 \%$, prestasi $50 \%$ dan tanggung jawab 56\%. Keseluruhan aspek rata-rata berada pada pencapaian hanya sebesar 54\% dengan kriteria sedang.

Dari penjelasan diatas, maka dapat dirumuskan masalahnya antara lain :

1. Bagaimana disiplin kerja di PT. Bank Danamon Tbk Cabang Bintaro ?

2. Bagaimana disiplin kerja di PT. Bank Danamon Tbk Cabang Bintaro ?

3. Adakah pengaruh disiplin kerja terhadap kinerja karyawan?

\section{KAJIAN TEORI}

\section{Disiplin Kerja}

Hasibuan (2012:194) yang dimaksud Disiplin kerja dalam peneltian ini adalah "Kesadaran dan kesediaan seseorang menaati semua peraturan perusahaan dan norma-norma sosial yang berlaku".

\section{Kinerja Karyawan}

Sesuai dengan pendapat Hasibuan (2012:95) yang dimaksud kinerja pegawai dalam penelitian ini dalah"Hasil kerja yang dicapaii setiap karyawan sehingga dapat memberikan kontribusi positif terhadap perusahaan/instansi”. 


\section{METODOLOGI PENELITIAN Populasi dan Sampel}

Populasi dalam penelitian ini adalah karyawan PT. Bank Danamon Tbk Cabang Bintaro. Pengambilan sampling digunakan teknik proporsional random sampling dan didapatkan jumlah sampel sebanyak 100 responden.

\section{Jenis dan Sumber Data}

Jenis data yang digunalan adalah kuantitatif yang sumber data primer dengan cara menyebar kuesioner yang selanjutnya dilakukan tabulasi dan analisis kelayakan serta data sekunder yang berasal dari berbagai literature keilmuan.

\section{Pengujian Instrumen Data}

Pengujian instrumen menggunakan uji validitas dan reliabilitas. Dari uji validitas dinyatakan valid terbukti dengan nilai $r$ hitung $>r$ tabel, demikian juga dengan uji reliabilitas.

\section{HASIL PENGUJIAN \\ Analisis Deskriptif}

Kriteria dari obyek yang diteliti berdasarkan pada tanggapan responden pada butir pertanyaan tentang disiplin kerja (X) diperoleh rata-rata skor 3,76, sedangkan variabel kinerja karyawan (Y) diperoleh rata-rata skor sebesar 3,90, ke dua variabel diperoleh semua skor berada pada rentang skala 3.40 - 4.19 dengan kriteria baik.

\section{Analisis Verivikatif}

\section{Analisis Regresi Linier Sederhana \\ Coefficients $^{\mathrm{a}}$}

\begin{tabular}{|l|r|r|r|r|r|}
\hline \multirow{2}{*}{ Model } & \multicolumn{2}{|c|}{$\begin{array}{c}\text { Unstandardized } \\
\text { Coefficients }\end{array}$} & $\begin{array}{c}\text { Standardized } \\
\text { Coefficients }\end{array}$ & & \\
\cline { 2 - 5 } & B & $\begin{array}{c}\text { Std. } \\
\text { Error }\end{array}$ & \multicolumn{1}{|c|}{ Beta } & $t$ & Sig. \\
\cline { 2 - 5 } Disiplin kerja(X) & .635 & .052 & .780 & 12.329 & .000 \\
\hline
\end{tabular}

Berdasarkan hasil perhitungan regresi diperoleh persamaan regresi linier berganda $\mathrm{Y}=14,736+0,635 \mathrm{X}$. Constanta bernilai positif, dengan demikian setiap ada perubahan kenaikan pada variabel disiplin kerja akan memiliki implikasi positif terhadap variabel kinerja karyawan.

\section{Analisis Koefisien Korelasi}

\section{Model Summary}

\begin{tabular}{|l|c|r|r|r|}
\hline Model & $\mathrm{R}$ & $\begin{array}{c}\mathrm{R} \\
\text { Square }\end{array}$ & $\begin{array}{c}\text { Adjusted } \mathrm{R} \\
\text { Square }\end{array}$ & $\begin{array}{c}\text { Std. Error of the } \\
\text { Estimate }\end{array}$ \\
\hline 1 & $.780^{\mathrm{a}}$ & .608 & .604 & 2.742 \\
\hline
\end{tabular}

Diperoleh $R$ sebesar 0,780 dengan demikian kedua variabel memiliki tingkat hubungan atau pengaruh KUAT.

\section{Analisis Koefisien Determinasi}

\section{Model Summary}

\begin{tabular}{|l|c|r|r|r|}
\hline Model & $\mathrm{R}$ & $\begin{array}{c}\mathrm{R} \\
\text { Square }\end{array}$ & \multicolumn{1}{c|}{$\begin{array}{c}\text { Adjusted R } \\
\text { Square }\end{array}$} & $\begin{array}{c}\text { Std. Error of the } \\
\text { Estimate }\end{array}$ \\
\hline 1 & $.780^{\mathrm{a}}$ & .608 & .604 & 2.742 \\
\hline
\end{tabular}

Diperoleh $R$-squared sebesar 0,608 dengan demikian kontirbusi pengaruh variabel $\mathrm{X}$ terhadap Y sebesar 60,8\% sedangkan sisanya sebesar $39,2 \%$ dipengaruhi oleh faktor lain.

\section{Pengujian Hipotesis (Uji t)}

Pengujian hipotesis menggunakan uji $t$ yaitu untuk menguji bagaimana pengaruh variabel bebas terhadap variabel terikatnya.

Rumusan Hipotesisnya adalah : Terdapat pengaruh positif dan signifikan antara disiplin kerja terhadap kinerja karyawan pada PT. Bank Danamon Tbk Cabang Bintaro.

\begin{tabular}{|l|r|r|r|r|r|}
\hline & \multicolumn{2}{|c|}{ Coefficients $^{\mathrm{a}}$} \\
& \multicolumn{2}{|c|}{$\begin{array}{c}\text { Unstandardized } \\
\text { Coefficients }\end{array}$} & $\begin{array}{c}\text { Standardized } \\
\text { Coefficients }\end{array}$ & & \\
\cline { 2 - 5 } Model & \multicolumn{1}{|c|}{$\mathrm{B}$} & \multicolumn{1}{c|}{$\begin{array}{c}\text { Std. } \\
\text { Error }\end{array}$} & \multicolumn{1}{|c|}{ Beta } & \multicolumn{1}{c|}{$\mathrm{t}$} & Sig. \\
\hline 1 (Constant) & 14.736 & 1.987 & & 7.416 & .000 \\
$\begin{array}{l}\text { Disiplin kerja } \\
\text { (X1) }\end{array}$ & .635 & .052 & .780 & 12.329 & .000 \\
\hline
\end{tabular}


Diperoleh nilai $t$ hitung $>t$ tabel (6.182 > 1.985), hal itu juga diperkuat dengan signifikansi $0,000<0,05$. Dengan demikian hipotesis pertama dapat diterima.

\section{PEMBAHASAN}

\section{Pembahasan Deskriptif}

Keadaan atau kriteria obyek yang diteliti berdasar pada variabel Disiplin Kerja (X) dan Kinerja Karyawan (Y) dari hasil kuesioner diperoleh rata-rata skor berada diantara rentang skala 3,40-4,19 dengan kriteria baik. Artinya masing-masing indikator memiliki jawaban atau penilaian yang beragam namun secara keseluruhan dalam kondisi mendapatkan tanggapan positif dari karyawan.

\section{Pembahasan Verifikatif \\ Pengaruh Disiplin Kerja (X) Terhadap Kinerja Karyawan (Y).}

Disiplin kerja berpengaruh posiitif terhadap kinerja karyawan, hal ini dibuktikan dengan persamaan regresi linier $\mathrm{Y}=14,736+0,635 \mathrm{X}$ dimana nilai konstanta bernilai positif dengan tingkat kekuatan hubungan sebesar 0,780 atau kuat. Adapun kontribusi pengaruhnya adalah 0,608 atau sebesar $60,8 \%$ sedangkan sisanya 39,2\% dipengaruhi oleh faktor lain. Pengujian hipotesis diperoleh $t$ hitung > t tabel atau $(12,329>1,984)$ hal itu juga dibuktikan dengan signifikansi $0,000<0,05$. Dengan demikian maka $\mathrm{H}_{0}$ ditolak dan $\mathrm{H}_{1}$ diterima.

Hasil penelitian ini konsisten dengan penelitian I Gusti Agung Ayu Maya, Murwaningsih, Sumaryanto dan Tari Wulandari dimana dalam penelitiannya menghasilkan kesimpulan bahwa variabel disiplin kerja terbukti berpengaruh positif dan signifikan terhadap kinerja karyawan, dan ini sesuai dengan pendapat Hasibuan (2012:194) dimana motivasi merupakan "Kesadaran dan kesediaan seseorang mentaati semua peraturan perusahaan dan norma-norma sosial yang berlaku". Pendapat ini selaras juga dengan Elya (2010:22) dimana disampaikan bahwa "Penilaian kinerja berguna untuk memperbaiki kinerja di masa yang akan datang, memberikan nilai umpan balik tentang kualitas kerja untuk kemudian mempelajari kemajuan perbaikan yang dikehendaki dalam kinerja".

\section{KESIMPULAN DAN SARAN Kesimpulam}

Dari analisis regresi diperoleh variabel disiplin kerja diperoleh konstanta bernilai positif diartikan jika ada perubahan kenaikan pada variabel disiplin kerja maka akan mengakibatkan variabel kinerja karyawan juga akan meningkat dengan kontribusi pengaruh yang positif dan signifikan.

Pengujian hipotesis baik secara parsial maupun simultan diperoleh nilai probability signifikansi $<0,05$, sehingga $\mathrm{H}_{0}$ ditolak dan $\mathrm{H}_{1}$ diterima dengan demikian terdapat pengaruh yang positif dan signifikan antara variabel disiplin kerja terhadap kinerja karyawan.

\section{Saran}

Kondisi variabel yang diteliti, tanggapan responden sudah baik, namun untuk lebih baik lagi disarankan bagi peneliti lain untuk menambahkan jumlah responden dan jumlah variabel yang diteliti agar lebih memiliki nilai yang representatif.

\section{DAFTAR PUSTAKA}

Andi Supangat, "Statistika dalam Kajian Deskriftif, Inferensi dan Non Parametric", Edisi Pertama, Kencana Prenada Media Group, Jakarta, 2011.

\begin{tabular}{ccrr} 
Anwar & Prabu & \multicolumn{2}{c}{ Mangukenegara, } \\
"Manajemen & Sumber & Daya \\
Manusia", & PT. & Remaja
\end{tabular} Rosdakarya, bandung, 2012.

Arief. M, "Metodologi Penetian", Rajawali Press, Jakarta, 2011. 
Bilson Simamora, "Panduan Riset Prilaku Konsumen", PT. Gramedia Pustaka, Jakarta, 2014.

Burhan Bugin, "Analisis Data Penelitian Kualitatif”, PT. Raja Grafindo Persada, Jakarta, 2013.

Darma Setyawan Salam, "Manajemen Pemerintahan Indonesia", Djambatan, Jakarta, 2011.

Edwin B Flippo, "Prinsip-Prinsip Sumber Daya Manusia”, Edisi ke Duabelas, Erlangga, Jakarta, 2011.

Edy Sutrisno, "Sumber Daya Manusia", PT. Gramedia, Surabaya, 2012.

Elya Lisnawati, "Komitmen Ortganisasi", Gramedia Pustaka Utama, Jakarta, 2010.

Gerry, Dessler "Human Resources Management", Prenticehall, International Inc, London, 2012..

Ghozali "Aplikasi Analisis Multivariate dengan Program SPSS”, Edisi Kelima, Badan Penerbit Undip, Semarang, 2011

Handoko, "Manajemen Personalia dan Sumberdaya Manusia”, Edisi Kelima, BPFE UGM, Yogyakarta, 2012.

Hariandja, Marihot T.E, "Manajemen Sumber Daya Manusia”, Grasindo, Jakarta, 2013.

Hasan Iqbal, "Analisis Data Dengan Statistik”, Bumi Aksara, Jakarta, 2013.

Hasibuan, "Manajemen SUmber Daya Manusia”, Haji Masagung, Jakarta, 2013.

Husen Umar, "Riset Pemasaran Dan Perilaku Konsumen”, PT. Gramedia Pustaka Utama, Jakarta , 2011.
Istijianto, "Aplikasi Praktis Riset Pemasaran”, Gramedia Pustaka Utama, Jakarta, 2010.

Jonathan Sarwono, "Metode Penelitian Kuantitatif Dan Kualitatif”, Graha Ilmu, Yogyakarta, 2012

Ladzi Safroni, "Manajemen dan Reformasi Pelayanan Publik dalam Konteks Birokrasi Indonesia", Aditya Media Publishing, Surabaya 2012.

Leo Sutanto, "Kiat Jitu Menulis Skripsi", Erlangga, Surabaya, 2013.

Margono, "Metodologi Penelitian Pendidikan”, Rineke, Jakarta, 2004.

Marwansyah, "Manajemen Sumber Daya Manusia”, PT. Alphabeta, Bandung, 2012.

Masri Sangarimbun dan Sultan Effendi, "Metode Penelitian Survei", LP3S, Jakarta, 2005.

Mathis, Robert. L \& Jackson John.H, "Manajemen Sumber Daya Manusia” Jilid 1, Salemba Empat, Jakarta, 2014.

Miftah Thoha, "Kepemimpinan Dalam Manajemen”, Edisi Pertama, PT. Raja Grafindo, Jakarta, 2007.

Panji Anaroga, "Mananajemen Bisnis", PT.Rineka Cipta, Semarang, 2011.

Robbins, S. \& Judge, T, “Organizational Behavior", Edisi keduabelas, , Prentice Hall, 2012.

Sadili Samsudin, "Manajemen Sumber Daya Manusia”, CV. Pustaka Setia, Jakarta, 2012.

Sedarmayanti. "Manajemen Sumber Daya Manusia, Reformasi Birokrasi dan Manajemen Pegawai Negeri Sipil”, 
Cetakan Kelima, PT Refika Aditama, Bandung, 2011.

Setiyawan dan Waridin, "Pengaruh Disiplin Kerja Karyawan dan Budaya Organisasi Terhadap Kinerja di Divisi Radiologi RSUP Dokter Kariadi", Semarang. JRB. Vol.2. No.2 Hal: 181-198. (2012

Siagian, Sondang "Kiat Meningkatkan Produktivitas Kerja”, PT. Rineka Cipta, Jakarta, 2012.

Singgih Santoso,"SPSS Statistik Parametik" Cetakan Kedua, PT. Elek Media 2012.

Sugiyono, "Metode Penelitian Kuantitatif Kualitatif dan $R$ \& $D$ ”, Penerbit CV. Alfabeta, Bandung, 2014.

Suharsimi Arikunto, "Prosedur Penelitian Suatu Pendekatan Praktek”, PT. Rineka Cipta, Jakarta, 2011.

Syofian Siregar, "Statistika Deskriptif Untuk Penelitian”, PT Raja Grafindo Persada, Jakarta, 2010.

Thomas S. dan Snell, ScottA, "Management The New Competitive", Landscape. Sixth Edition. McGraw Hill. New York, 2013.

Veithzal Rivai, "Manajemen Sumber Daya Manusia Untuk Perusahaan”, Raja Grafindo Persada, Jakarta, 2012.

Wawan S. Suherman, "Kurikulum Berbasis Kompetensi Pendidikan Jasmani Teori dan Praktik Pengembangan", FIK UNY, Yogyakarta, 2012.

Wibowo, "Manajemen Kinerja”, PT. Raja Grafindo Persada, Jakarta, 2012.

Windy Aprilia dan Gunasti Hudiwinarsih, "Teori Kompensasi, Motivasi dan Komitmen Organisasi”, Gramedia, Jakarta, 2012.
Wirawan, “.Evaluasi Kinerja Sumber Daya Manusia (Teori Aplikasi dan Penelitian)". Salemba Empat, Jakarta, 2009

\section{Tesis/Jurnal}

Ananda Pambudi, Tesis, "Pengaruh Motivasi, Disiplin Kerja, Komitmen Organisasi dan Kompensasi Terhadap Kinerja karyawan pada PT. Mahkota

Industries", Universitas Negeri Surakarta, 2014.

Bambang Sulistyo, Tesis, "Pengaruh Motivasi, Disiplin Kerja dan Komitmen Organisasi Terhadap Kinerja Karyawan Pada PT. Pan Brothers Tangerang", Universitas Mercubuana, Jakarta, 2014.

Baskoro, Tesis, "Pengaruh Motivasi Kerja, Kepuasan Kerja dan Komitmen Organisasi Terhadap Kinerja Karyawan PT. Panama Gatra", Universitas Diponegoro, Semarang, 2014.

Prabasari, I Gusti Agung Ayu Maya dan I Gusti Salit Ketut Netra, Tesis, "Pengaruh Motivasi, Disiplin Kerja dan Komunikasi Terhadap Kinerja Karyawan Pada PT PLN (Persero) Distribusi Bali”, 2013.

Siswandi, Tesis, "Pengaruh Kepemimpinan, Komunikasi Internal dan Motivasi Kerja Terhadap Kinerja Karyawan Pand's Collection Semarang”, 2014.Tari Wulandari, Tesis, "Pengaruh Motivasi Kerja, Disiplin Kerja, Budaya Kerja dan Komitmen Organisasi

Terhadap Kinerja Karyawan Pada PT. Solusindo Pratama", Universitas Diponegoro Semarang, 2014 


\section{Perundang-Undangan}

Inpres No.6/2014, tentang peningkatan daya saing menghadapi Masyarakat Ekonomi ASEAN.

Keputusan Presiden No.37/2014 tentang regulasi pemerintah dalam upaya untuk meningkatkan daya saing nasional dan menghadapi MEA.

Peraturan Bank Rakyat Indonesia tahun 1998 tentang disiplin karyawan bank.

Undang-Undang Dasar Negara Republik Indonesia Tahun 1945.

Undang-Undang Perbankan No. 7 tahun 1992 dan Peraturan Pemerintah RI No. 21 tahun 1992 tentang status Bank Rakyat Indonesia berubah menjadi perseroan terbatas.

Undang-Undang Perbankan No.10 tahun 1998 Pasal 1 tentang badan usaha yang menghimpun dana dari masyarakat dalam bentuk simpanan dan perlindungan nasabah. 